\title{
Sleep in the Land the of Midnight Sun and Polar Night The Tromsø Study 2015-2016
}

\author{
Børge Sivertsen ${ }^{*} 1,2,3$, Oddgeir Friborg ${ }^{4}$, Ståle Pallesen ${ }^{5,6,7}$, Øystein Vedaa ${ }^{1,3,8,9}$, Laila \\ Arnesdatter Hopstock ${ }^{10}$
}

${ }^{1}$ Department of Health Promotion, Norwegian Institute of Public Health, Bergen, Norway

${ }^{2}$ Department of Research \& Innovation, Helse Fonna HF, Haugesund, Norway

${ }^{3}$ Department of Mental Health, Norwegian University of Science and Technology, Trondheim, Norway

${ }^{4}$ Department of Psychology, UiT The Arctic University of Norway, Troms $\phi$, Norway

${ }^{5}$ Department of Psychosocial Science, Faculty of Psychology, University of Bergen, Bergen, Norway

${ }^{6}$ Norwegian Competence Center for Sleep Disorders, Haukeland University Hospital, Bergen, Norway

${ }^{7}$ Optentia, Vaal Triangle Campus of the North-West University, South-Africa

${ }^{8}$ Voss District Psychiatric Hospital, NKS Bjфrkeli, Voss, Norway

${ }^{9}$ Department of Research and Development, St Olavs University Hospital, Trondheim, Norway

${ }^{10}$ Department of Community Medicine, Faculty of Health Sciences, UiT The Arctic University of Norway, Troms $\phi$, Norway

* Corresponding author: Professor Børge Sivertsen, Department of Health Promotion, Norwegian Institute of Public Health, Bergen, Norway, Postboks 973 Sentrum, 5808 Bergen, Norway, E-mail: borge.sivertsen@fhi.no 


\begin{abstract}
While some diseases and human behaviors fluctuate consistently with season, the extent of seasonal variations in sleep, especially at high latitudes, is less consistent. We used data from a geographic region $\left(69^{\circ}\right.$ North) with extremely large seasonal differences in daylight that had the participants blinded for the current study's hypotheses. Data were derived from the Troms $\varnothing$ Study (2015-2016), an ongoing population-based study in Northern Norway comprising citizens aged 40 years and older $(n=21,083$, participation $=64.7 \%$ ). The sleep parameters included bedtime, rise time, sleep onset latency (SOL), and total sleep time. Insomnia was defined according to recent diagnostic criteria (International Classification of Sleep Disorders; ICSD-3). We found some evidence of monthly or seasonal variation in sleep problems. Insomnia was most common during the winter months among men, but not women. No seasonal or monthly effects were observed for sleep duration. SOL was slightly longer during the winter months, but the differences were small and hardly of any clinical relevance. The small or nonexisting seasonal variation in sleep and sleep difficulties indicate that extreme seasonal variation in daylight is of little influence on sleep status. The city of Tromsø is a modern city with considerable level of artificial light, which may contribute to the observed rather stabile sleep patterns throughout the year.
\end{abstract}

Keywords: Epidemiology, Insomnia, Sleep duration, Seasonality, Environmental light, High latitude 


\section{INTRODUCTION}

Life above the Arctic Circle implies living with extreme variation in daylight throughout the year. For example, in Troms $\varnothing$, the largest city in Northern Norway that is situated at $69^{\circ}$ Northern latitude, the sun remains below the horizon (Polar Night) for two months, from mid-November to midJanuary. Conversely, during summer the sun stays above the horizon (Midnight Sun) for nearly 60 continuous days. Such variation in natural illumination has been suggested to cause disruptions of the behavior of humans, most notably mood and sleep patterns (Kasper et al. 1989), a phenomenon commonly referred to as seasonality (Rosenthal et al. 1984). While some diseases and human behaviors, such as influenza (Weinberger et al. 2012) and physical activity (Shephard \& Aoyagi, 2009) show seasonal patterns, the evidence of seasonal effects on mood and sleep is mixed. In a recent systematic review covering 41 studies, Øverland et al. found some support for seasonal variation in clinical depression, but there was no convincing evidence for a seasonal effect regarding depressive symptoms at the population level (Overland et al. 2019). Far fewer studies have explored possible seasonality in sleep and sleep problems, with the majority of studies having been conducted in the Nordic countries, characterized by Polar Night and Midnight Sun.

Earlier studies of the general population in Troms $\emptyset$ have found more symptoms of insomnia and fatigue during the winter as compared to the summer season (Husby \& Lingjaerde 1990; Johnsen et al. 2012; Johnsen et al. 2013; Friborg et al. 2014). However, the magnitude of the seasonal variation in insomnia seems to be in the weak-to-moderate range, whereas seasonal changes in fatigue may be more pronounced (Friborg et al. 2014; Friborg et al. 2018). In contrast, findings from another large populationbased study in Norway (the HUNT3 study; at $63-65^{\circ}$ Northern latitude) show no evidence of monthly variation, neither in insomnia prevalence nor time spent in bed (Sivertsen et al. 2011), despite large variation in daylight across the year (4 to $21 \mathrm{~h}$ ). Adding to the inconsistency of reports, a Finish population-based study found that $20 \%$ of its participants had worse sleep quality during the summer, while estimates for the remaining three seasons were around 5-10\% (Ohayon \& Partinen 2002).

Studies conducted in more temperate zones have also explore possible seasonal variation in sleep. For example, a recent Japanese study found longer sleep duration in winter compared to summer; but, the difference was relatively modest (11 min) (Suzuki et al. 2019), and another nationwide Japanese study found no significant association between seasonality and insomnia prevalence (Itani et al. 2016). An additional Japanese study that collected objective sleep data (contactless biomotion sensors) over 3 $\mathrm{y}$ found no evidence of seasonal variation in bedtime, whereas a seasonal effect was observed for wake after sleep onset (WASO) and sleep efficiency, with a worsening of sleep being observed both during summer and winter. However, the authors of this study suggested that these differences were more related with variations in temperature rather than daylight (Hashizaki et al. 2018). Another large study examining human activity, including total and nocturnal sleep time, across several European countries and the USA, found small and non-significant differences in sleep between winter and summer (Martin- 
Olalla 2019). A prospective study comparing students in Troms $\varnothing$ and in Ghana $\left(5^{\circ} \mathrm{N}\right)$ found small and inconsistent changes in the sleep for the Ghanaian students between January and August, whereas students in Troms $\emptyset$ reported more insomnia and fatigue as well as delays in sleep onset and rise times in January than in August. However, no seasonality regarding total sleep time was found, neither in Ghana nor in Troms $\varnothing$ (Friborg et al. 2012).

Taken together, it remains unclear to what extent there are any monthly or seasonal variations in sleep and sleep problems across the year at high latitudes. Based on these considerations, the aim of the current study was to examine seasonal variations in a range of self-reported sleep parameters in a geographical region with very large seasonal differences in daylight. To accomplish this, we used data from a large national representative health survey of the Troms $\varnothing$ Study 2015-2016 comprising 21083 individuals who were blinded for the current research question.

\section{METHODS}

\section{Setting \& participants}

The municipality of Troms $\varnothing$ in Norway is located at $69^{\circ}$ Northern latitude, $300 \mathrm{~km}$ above the Arctic Circle, and is the largest city in the world at this latitude. The city undergoes extreme variation in natural daylight throughout the year. Although the sun does not rise at all during the Polar Night (between late November to late January), it is not pitch-black during midday. The sky is deep blue, but the light intensity is exceedingly low and of short duration. During the summer, the sun is visible for the full $24 \mathrm{~h}$ during the two months of the Midnight Sun (Polar Day) period that lasts from late May to late July. After this, the days turn progressively shorter until emergence of the Polar Night, and the cycle is repeated. Figure 1 illustrates the annual variations in daytime light in Troms $\varnothing$ compared to large cities situated at other latitudes.

Please insert Figure 1 about here

The Troms $\varnothing$ Study is an ongoing population-based health study conducted in the municipality of Troms $\varnothing$, Norway, with seven surveys conducted to date (Troms $\varnothing 1-7,1974-2016$, with participation varying between $65-79 \%$ ). Total birth cohorts and representative population samples have been invited and 45473 women and men have participated in at least one survey. Data collections included a clinical evaluation, biological sampling, and completion of interviews and questionnaires (Jacobsen et al. 2012). The submission date of the questionnaires (containing all sleep data) was used to define the month of 
examination in the current study. In Troms $\varnothing 7$ (2015-2016), all citizens aged $\geq 40 \mathrm{y}$ ( $\mathrm{n}=32$ 591) living in the municipality were invited, of which 21083 women and men aged 40-99 y participated (participation: 64.7\%).

The Tromsø 7 study was approved by the Regional Committee for Medical Research Ethics (REC North ref. 2014/940), and it conforms to the ethical standards for biological rhythm research studies outlined by Portaluppi et al. (2010).

\section{Instruments}

\section{$\underline{\text { Sleep measures }}$}

Questions about sleep and education were included in a general questionnaire completed online, either before the visit or at the study site. Details of the sleep measures and results from the Troms $\varnothing$ Study are published elsewhere (Sivertsen et al. 2020). In short, we used a slightly modified version of the Bergen Insomnia Scale (Pallesen et al. 2008) to assess symptoms of insomnia. The original Bergen Insomnia Scale (BIS) included six items that correspond to the diagnostic criteria for insomnia found in the fourth edition of the Diagnostic and Statistical Manual for Mental Disorders (DSM-IV) (American Psychiatric Association 1994). Each item is scored using a scale from 0 to 7, referring to the number of days per week the respondents experience a specific symptom. The first four items (prolonged sleep onset, difficulties maintaining sleep, early morning awakening, and non-restorative sleep) assess nocturnal symptoms of insomnia (DSM-IV inclusion criterion A for insomnia), whereas the last two items reflect daytime sleepiness or tiredness (affecting school, work, or private life) and dissatisfaction with sleep (DSM-IV inclusion criterion B for insomnia). BIS has demonstrated good psychometric properties (Pallesen et al. 2008). The time frame in the original BIS was last month, which corresponded to the criterion found in the DSM-IV. However, according to the $5^{\text {th }}$ and most recent revision of the DSM (American Psychiatric Association 2013) as well as the $3^{\text {rd }}$ and latest version of the International Classification of Sleep Disorders (ICSD-3) (American Academy of Sleep Medicine 2014), the minimum symptom duration for chronic insomnia is raised to at least three months. Therefore, we added a question asking the participants about the duration of their sleep problems. Another diagnostic change concerns non-restorative sleep, which has been discarded as an insomnia criterion both in the DSM-5 (American Psychiatric Association 2013) and the ICSD-3 (American Academy of Sleep Medicine 2014). Accordingly, the BIS item reflecting this symptom was disregarded in the current insomnia operationalization. As such, the included items adhered to ICSD-3 insomnia disorder criteria. Chronic insomnia was defined as being present if the participants reported: 1) at least one of the three nocturnal symptoms $\geq 3$ nights/week, and 2) one or both of the two daytime (daytime sleepiness/tiredness and dissatisfaction with sleep) symptoms $\geq 3$ days/week, and 3) reporting a duration of the sleep problems for $\geq 3$ months. In the current study, we examined both chronic insomnia disorder as well as each of the 
5 BIS items, separately.

Self-reported bed- and rise time were provided by the respondents in terms of hours and minutes and were reported separately for weekend and weekdays. Time in bed (TIB) was calculated by subtracting bedtime from rise time. Sleep onset latency (SOL) was reported in minutes. Based on the data, a five-point categorical SOL variable was created: 1) "less than 15 minutes", "15-29 minutes", "30-59 minutes", "60-119 minutes", and "120 minutes or longer" for inclusion in specific analyses. Sleep duration was defined as TIB minus SOL. In addition to being used as a continuous variable, sleep duration was also used categorically $(<5: 00 \mathrm{~h}, 5: 00-5: 59 \mathrm{~h}, 6: 00-6: 59 \mathrm{~h}, 7: 00-7: 59 \mathrm{~h}, 8: 00-8: 59 \mathrm{~h}$, and $\geq 9: 00 \mathrm{~h})$.

\section{Statistics}

IBM SPSS Statistics 26 for Windows (SPSS Inc., Chicago, Ill) was used to run Pearson ChiSquare Tests, univariate analyses of variance, and logistic regression analyses to examine the association between sleep characteristics and month and season of examination. Estimated marginal means (EMM) and estimates of prevalence rates/proportions were also computed, adjusting for age, education, and income. In order to examine changes in sleep, indices related to months or seasonality (winter December, January and February; spring - March, April, and May, summer - June, July, and August, autumn - September, October, and November), we performed additional contrast analyses defining a linear and a quadratic trend for the month and season variables, respectively. A significant linear trend indicates a rising or declining trend from January to December, whereas a significant quadratic trend indicates a curvilinear U-shaped (or an inverted form) trend across months or seasons, respectively.

\section{RESULTS}

In all, 21083 participants were included (51.9\% women and $48.1 \%$ men, mean age of $57.3 \mathrm{y}$ ( $\mathrm{SD}=11.5 \mathrm{y}$ ). A majority of the participants had completed a high school degree (77.2\%). As detailed in Table 1, the mean number of examinations per month was 1734 (men: $n=824$ and women $n=912$ ).

Insert Table 1 about here

\section{Monthly and seasonal variations in insomnia disorder}

The month with the highest prevalence of ICSD-3 insomnia disorder was June for women (26.6\%) and February for men (18.4\%), while the month with lowest prevalence was July for women 
(19.7\%) and March and August for men (both 13.3\%). As shown in the adjusted analyses in Table 2, there was a small, but significant, curvilinear (quadratic) effect of examination month for men ( $\mathrm{p}=.043$ ), but not women $(\mathrm{p}=.209)$. In terms of seasonal effects, a similar sex-specific curvilinear pattern was found, with significantly higher insomnia prevalence in winter (17.4\%) and autumn (16.1\%) among men, compared to both spring (14.3\%) and summer (13.6\%; see Table 2 for details). The uppermost graph of Figure 2 shows the sex-specific age-adjusted insomnia prevalence based on gliding means. Although a weak curvilinear trend is observed for both men and women, the $95 \%$ confidence intervals for the prevalence estimates each month overlapped with the overall mean, indicating there was no significant effect of examination month for these analyses.

Insert Table 2 and Figure 2 about here

\section{Monthly and seasonal variations in sleep duration}

There were no significant effects of either examination month or season on sleep duration, as detailed in the fully adjusted analyses in Table 3. The difference between the month with the longest and shortest sleep duration was $4 \mathrm{~min}$ for women and $7 \mathrm{~min}$ for men. Also, there were no significant linear or quadratic trends for either women or men. The middle graph in Figure 2 shows the age-adjusted sleep duration for men and women based on gliding means.

Insert Table 3 about here

\section{Monthly and seasonal variations in sleep onset latency (SOL)}

Table 4 depicts the average SOL for each month and season. Although statistically significant curvilinear effects were observed when examined by month for both men and women $(p<.001)$, the average difference between the months with the longest and shortest SOL was small (3-4 min). The bottom graph in Figure 2 shows a similar pattern; for the estimated gliding means, only January was significantly different from the average SOL for the whole year, as indicated by the overlapping $95 \%$ confidence intervals. In terms of seasonal effects, the observed SOL was significantly longer during winter (23 min for women and $19 \mathrm{~min}$ for men) compared to the other seasons (women 21-22 min and men 16-17 min; see Table 4 for detail). 


\section{Monthly and seasonal variations in insomnia symptoms}

When examining each of the 5 insomnia items included in the insomnia proxy, we found evidence of some seasonal differences. The two items assessing difficulties initiating and maintaining sleep (DIMS), as well as sleep dissatisfaction, were more frequent in winter compared to the other seasons. Daytime tiredness did not vary throughout the year (see Table 5 for details).

Insert Table 5 about here

\section{DISCUSSION}

Using data from a geographic region with extremely large seasonal differences in daylight across the year, this fully blinded large population-based study examined monthly and seasonal variation in sleep and sleep problems. We found some evidence of a monthly and seasonal pattern in sleep problems. While insomnia was slightly more common in winter among men (but not women), no significant effects of either examination month or season were found for sleep duration. SOL was slightly longer during the winter than other months, but the difference was small, and of little clinical significance. Investigating the BIS items individually, the two items assessing DIMS were more common during winter, while EMA was more common in the spring (only for women), suggesting a circadian phase delay during the months with little light as compared to the ones of brighter months.

Previous studies of seasonal differences in sleep and insomnia have shown mixed results, with some studies suggesting that insomnia may be more prevalent during the winter months (Pallesen et al. 2001; Friborg et al. 2014), whereas others have found no seasonal effect (Sivertsen et al. 2011; Itani et al. 2016), and even an opposite trend (Ohayon \& Partinen 2002). Also in the current study, the findings were mixed, with some evidence of a small seasonal effect for the insomnia variables, but not so much for actual sleep duration and SOL. The heterogeneity of study designs make comparisons across studies difficult. For example, several studies have been conducted in Japan (Itani et al. 2016; Hashizaki et al. 2018; Suzuki et al. 2019), a country with relatively little variation in hours of daylight throughout the year ( $<5 \mathrm{~h}$ difference between December and June). As also suggested by Suzuki et al. (Suzuki et al. 2019), it is more likely that the observed differences in those studies may be more related to seasonal differences in temperature, rather than by differences in daylight. In contrast to some earlier studies 
(Kasper et al. 1989; Volkov et al. 2007) that have found up to half an hour longer sleep duration in winter compared to summer, we found no evidence of this pattern in the current study, with a difference of only 4 min between the months with the longest and shortest sleep duration. These findings are also in line with most previous studies in Troms $\varnothing$ (Friborg et al. 2012, 2014, 2018; Johnsen 2013), of which the studies of Friborg et al. used a prospective seasonal design based on weekly sleep log recordings. While we can only speculate about the reasons behind the observed differences, we cannot disregard the possibility that study design may play a role. Most previous studies in this field, including those employing the frequently used Seasonal Pattern Assessment Questionnaire (SPAQ) (Rosenthal, Bradt et al., 1987), have asked study participants retrospectively if they think their sleep quality varies with the seasons. Such an approach implies that the subjects are not blinded to the research hypothesis, and recall bias may influence the findings.

Insofar as this this study did not demonstrate seasonal variations in sleep (and sleep difficulties), this may reflect that effect of artificial indoor lighting and light blocking drapes that contribute to maintain a more or less constant sleep pattern across seasons - despite the major changes in the natural light-dark cycle and in contrast to what is seen in other mammals (Barre \& Petter-Rousseaux 1988). However, we did find some evidence of a seasonal pattern when examining the insomnia operationalization and each of the BIS items individually. In fact, the two items assessing difficulties initiating and maintaining sleep (DIMS) were more frequent during winter months, while early morning awakenings (EMA) were more common during spring. This is consistent with previous studies conducted in Troms $\varnothing$, showing a delay of the main sleep episode during winter compared to summer (Husby \& Lingjaerde 1990; Johnsen et al. 2012; Johnsen et al. 2013; Friborg et al. 2014). Most likely, this reflects a lack of proper entraiment of the circadian rhythm during the Polar Night (Lowden et al. 2019).

\section{Methodological considerations}

The strengths of the current study include the combination of a large sample size, high participation (64.7\%), representativeness of the sample, as well as detailed sleep measures. The latter comprises both close approximation of chronic insomnia disorder according to the ICDS-3 (American Academy of Sleep Medicine 2014), as well as a more detailed approximation of actual sleep duration (as opposed to merely assessing TIB). In relation to this, the timeframe of all sleep items, expect the BIS items, in the current study referred to the participants' usual sleep problem/behavior, with no further specification of timing (last week or month etc.). However, we cannot disregard the possibility that some participants may refer to sleep problems experienced some time before filling out the questionnaire, and not only current sleep problems, which may have contributed to some degree of smoothing of possible differences in the monthly sleep data. For that reason, the reported monthly and seasonal variation may have been somewhat suppressed. Another strength is that, unlike most studies on seasonality, all 
participants in the current study were fully blinded to the specific research questions, eliminating the possibility of demand characteristics (Orne 1962), which is difficult to avoid in studies asking specifically about seasonality. The study was, in fact, double-blinded, as the hypothesis for the current study was not a part of the research protocol at the time of data collection.

Some study limitations should also be noted. First, all of the data used in the current study were based on self-report, with no objective sleep measures or clinician-verified information available to corroborate the findings. Second, we could not conduct analyses of non-responders, which could have improved the generalizability of the estimates further. Third, participants in the present study were all $>40 \mathrm{y}$ of age, which limits the generalizability to those being younger, which is an important point as previous studies has shown age-dependent effects of season on sleep (Thorleifsdottir et al. 2002). Fourth, employment status was not assessed. There is a possibility that this could influence the findings, although we consider it unlikely. Finally, we did not assess WASO in this study, which may have overestimated the total sleep duration estimates. 


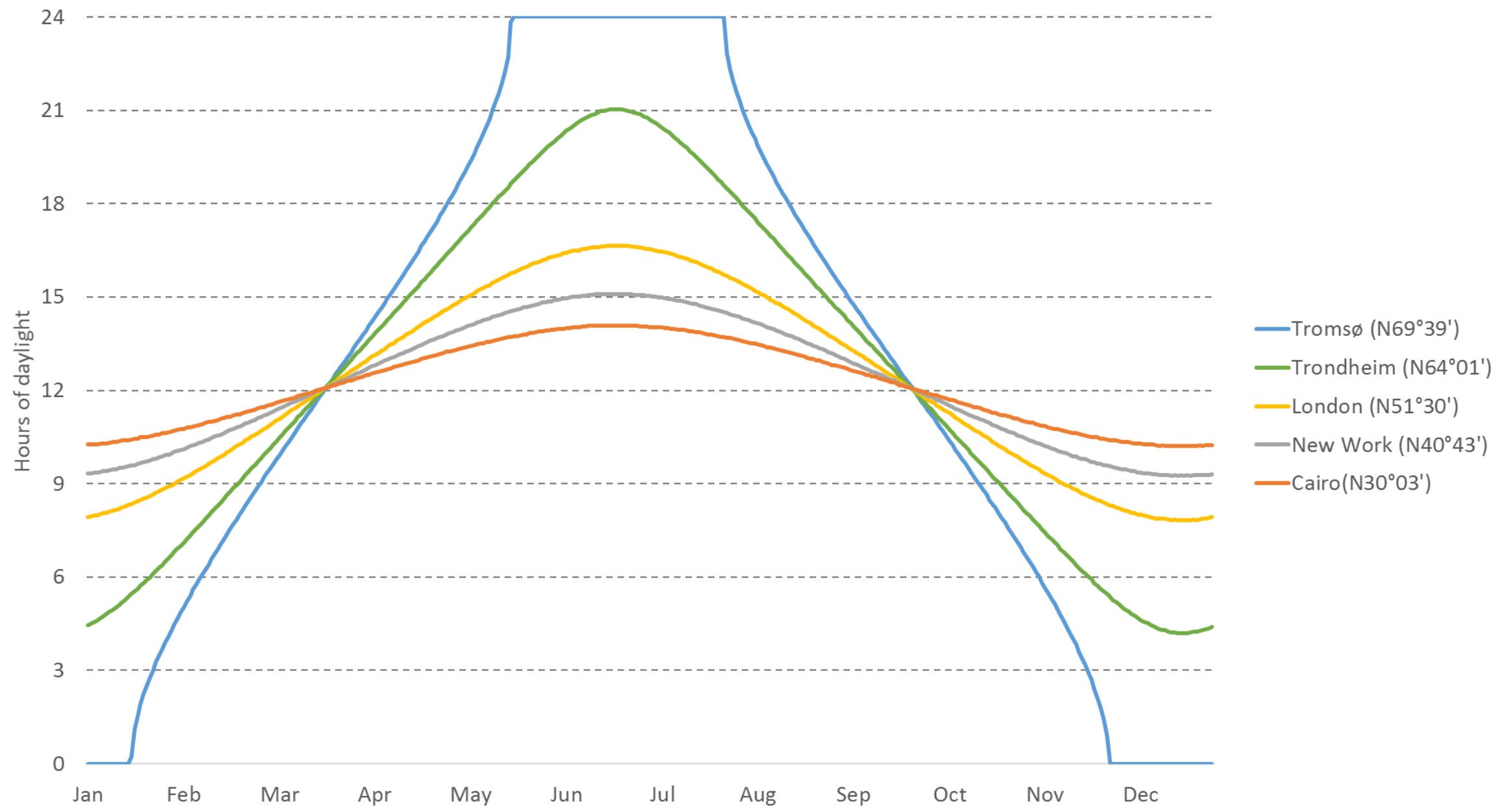

Figure 1. Monthly variations in hours of daylight on different latitudes. Source: Astronomical Applications Dept. U. S. Naval Observ. 

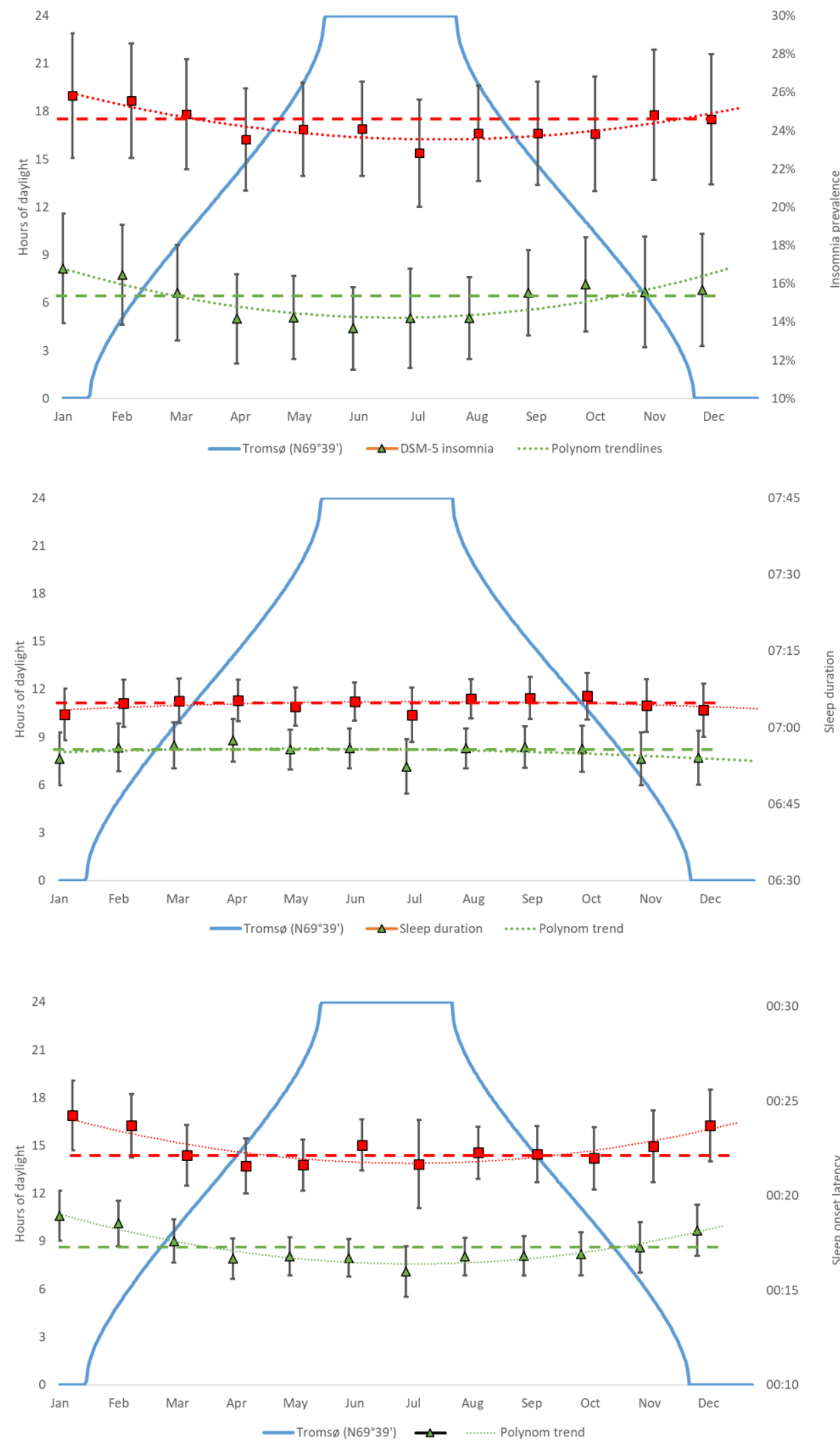

Figure 2. Monthly variations of ICSD-3 insomnia prevalence (right axis above), weekday sleep duration (right axis middle), and sleep onset latency (right axis below), and hours of daylight in the municipality of Troms $\varnothing$ (left axis). The error bars represent the $95 \%$ confidence intervals based on gliding Estimated Marginal Means (EMM; adjusted for age). The dotted lines represent the overall mean for the three sleep variables for men (green) and women (red). The Tromsø Study 2015-16. The blue line shows hours of daylight. 
Table 1. Population Characteristics (Absolute Numbers). The Tromsø Study 2015-16.

\begin{tabular}{lcc}
\hline & Men & Women \\
\hline Examination month (submission of sleep questionnaire) & \\
January & 877 & 789 \\
February & 790 & 706 \\
March & 840 & 795 \\
April & 1183 & 1041 \\
May & 1279 & 1075 \\
June & 1419 & 1145 \\
July & 231 & 192 \\
August & 1165 & 1085 \\
September & 1147 & 1127 \\
October & 904 & 865 \\
November & 620 & 619 \\
December & 499 & 450 \\
Average & 499 & 450 \\
Examination season & & \\
Winter & 2611 & 2671 \\
Spring & 1945 & 2166 \\
Summer & 2911 & 3302 \\
Autumn & 2815 \\
\hline
\end{tabular}


Table 2. Monthly and seasonal variations in prevalence rates@ of ICSD-3 insomnia@ by gender.

\begin{tabular}{llllll}
\hline Women & \multicolumn{5}{c}{ Men } \\
\hline$\%$ & SD & $(95 \% \mathrm{Cl})$ & $\%$ & SD & $(95 \% \mathrm{Cl})$ \\
\hline
\end{tabular}

\section{Month}

$\begin{array}{lllllll}\text { January } & 25.5 & 43.6 & (22.4-28.5) & 17.8 & 38.1 & (15.1-20.6) \\ \text { February } & 26.4 & 44.2 & (23.1-29.6) & 18.4 & 38.9 & (15.4-21.3) \\ \text { March } & 25.0 & 43.3 & (21.9-28.1) & 13.3 & 33.9 & (10.8-15.7) \\ \text { April } & 23.7 & 42.7 & (21.2-26.3) & 15.2 & 35.8 & (12.9-17.5) \\ \text { May } & 24.0 & 42.7 & (21.6-26.5) & 14.1 & 34.6 & (12.0-16.3) \\ \text { June } & 26.6 & 44.2 & (24.1-29.0) & 13.6 & 34.3 & (11.5-15.6) \\ \text { July } & 19.7 & 39.9 & (14.1-25.2) & 15.1 & 35.8 & (9.9-20.3) \\ \text { August } & 23.5 & 42.5 & (20.9-26.1) & 13.3 & 34.3 & (11.3-15.4) \\ \text { September } & 22.7 & 41.8 & (20.0-25.2) & 15.7 & 36.8 & (13.6-17.9) \\ \text { October } & 25.6 & 43.6 & (22.6-28.7) & 17.4 & 37.9 & (14.8-20.0) \\ \text { November } & 23.5 & 42.6 & (20.0-27.1) & 15.1 & 35.7 & (12.1-18.0) \\ \text { December } & 24.5 & 43.2 & (20.5-28.4) & 15.2 & 35.7 & (11.7-18.6)\end{array}$

Monthly trend (polynomial contrast)

$\begin{array}{lll}\text { Linear } & \mathrm{p}=.263 & \mathrm{p}=.380 \\ \text { Quadratic } & \mathrm{p}=.209 & \mathrm{p}=. \mathbf{0 4 3}\end{array}$

$\begin{array}{lllllll}\text { Season } & \% & \text { SD } & (95 \% \mathrm{Cl}) & \% & \mathrm{SD} & (95 \% \mathrm{Cl}) \\ \text { Winter } & 25.6^{\mathrm{a}} & 43.7 & (23.6-27.5) & 17.4^{\mathrm{a}} & 37.8 & (15.7-19.2) \\ \text { Spring } & 24.2^{\mathrm{a}} & 42.8 & (22.6-25.7) & 14.3^{\mathrm{b}} & 34.8 & (13.0-15.6) \\ \text { Summer } & 24.7^{\mathrm{a}} & 43.2 & (23.0-26.4) & 13.6^{\mathrm{b}} & 34.4 & (12.2-15.0) \\ \text { Autumn } & 23.9^{\mathrm{a}} & 42.6 & (22.1-25.6) & 16.1^{\mathrm{a}} & 36.9 & (14.7-17.6)\end{array}$

Seasonal trend (polynomial contrast)
Linear
$\mathrm{p}=.285$
$p=.183$
Quadratic
$\mathrm{p}=.802$
$p<.001$

@ Estimated prevalence rates/proportions are adjusted for age, education, and income.

Significant differences between seasons are indicated for each row in the table using subscript letters ( ${ }^{a, b, c,}$ etc), calculated at the .05 significance level. 
Table 3. Monthly and seasonal variation of sleep duration@ in hours and minutes by gender.

\begin{tabular}{|c|c|c|c|c|c|c|}
\hline & \multicolumn{3}{|c|}{ Women } & \multicolumn{3}{|l|}{ Men } \\
\hline & $\overline{\text { EMM }}$ & SD & $(95 \% \mathrm{Cl})$ & EMM & SD & $(95 \% \mathrm{Cl})$ \\
\hline \multicolumn{7}{|l|}{ Month } \\
\hline January & 07:05 & $1: 10$ & $(07: 00-07: 10)$ & $06: 54$ & $1: 04$ & $(06: 50-06: 59)$ \\
\hline February & 07:06 & $1: 07$ & $(07: 01-07: 11)$ & $06: 54$ & $1: 05$ & $(06: 49-06: 59)$ \\
\hline March & 07:09 & $1: 04$ & $(07: 04-07: 14)$ & $06: 58$ & $1: 03$ & $(06: 53-07: 03)$ \\
\hline April & 07:05 & $1: 02$ & $(07: 01-07: 19)$ & $06: 55$ & $1: 06$ & $(06: 51-06: 59)$ \\
\hline May & 07:07 & $1: 04$ & $(07: 03-07: 10)$ & $06: 57$ & $1: 05$ & $(06: 53-07: 01)$ \\
\hline June & 07:05 & $1: 09$ & $(07: 01-07: 09)$ & $06: 53$ & $1: 02$ & $(06: 49-06: 57)$ \\
\hline July & 07:01 & $1: 04$ & $(06: 52-07: 10)$ & $06: 51$ & $1: 07$ & $(06: 41-07: 00)$ \\
\hline August & 07:09 & $1: 08$ & $(07: 05-07: 13)$ & $06: 56$ & $1: 01$ & $(06: 52-07: 00)$ \\
\hline September & 07:07 & $1: 07$ & $(07: 03-07: 12)$ & $06: 57$ & $1: 06$ & $(06: 53-07: 01)$ \\
\hline October & 07:06 & $1: 01$ & $(07: 02-07: 11)$ & $06: 53$ & $1: 07$ & $(06: 49-06: 58)$ \\
\hline November & 07:08 & $1: 05$ & $(07: 02-07: 13)$ & $06: 53$ & $1: 06$ & $(06: 48-06: 59)$ \\
\hline December & 07:03 & $1: 12$ & $(06: 57-07: 09)$ & $06: 51$ & $1: 05$ & $(06: 45-06: 57)$ \\
\hline Monthly trend & \multicolumn{6}{|c|}{ (polynomial contrast) } \\
\hline Linear & \multicolumn{3}{|l|}{$p=.775$} & \multicolumn{3}{|l|}{$\mathrm{p}=.239$} \\
\hline Quadratic & \multicolumn{3}{|l|}{$p=.804$} & \multicolumn{3}{|l|}{$\mathrm{p}=.475$} \\
\hline
\end{tabular}

\section{Season}

$\begin{array}{lllllll}\text { Winter } & 07: 05^{\mathrm{a}} & 1: 09 & (07: 02-07: 08) & 06: 53^{\mathrm{a}} & 1: 05 & (06: 51-06: 56) \\ \text { Spring } & 07: 07^{\mathrm{a}} & 1: 03 & (07: 04-07: 09) & 06: 57^{\mathrm{a}} & 1: 05 & (06: 54-06: 59) \\ \text { Summer } & 07: 06^{\mathrm{a}} & 1: 08 & (07: 04-07: 09) & 06: 54^{\mathrm{a}} & 1: 02 & (06: 51-06: 57) \\ \text { Autumn } & 07: 07^{\mathrm{a}} & 1: 05 & (07: 04-07: 10) & 06: 55^{\mathrm{a}} & 1: 06 & (06: 52-06: 57)\end{array}$

Seasonal trend (polynomial contrast)

$\begin{array}{lll}\text { Linear } & \mathrm{p}=.313 & \mathrm{p}=.782 \\ \text { Quadratic } & \mathrm{p}=.741 & \mathrm{p}=.381\end{array}$

@ Estimated marginal means are adjusted for age, education, and income.

Significant differences between seasons are indicated for each row in the table using subscript letters (a,b,c, etc), calculated at the .05 significance level. 
Table 4. Monthly and seasonal variation of sleep onset latency ${ }^{@}$ in minutes by gender. The Tromsø Study 20152016.

\begin{tabular}{|c|c|c|c|c|c|c|}
\hline & \multicolumn{3}{|c|}{ Women } & \multicolumn{3}{|l|}{ Men } \\
\hline & EMM & SD & $(95 \% \mathrm{Cl})$ & EMM & SD & $(95 \% \mathrm{Cl})$ \\
\hline \multicolumn{7}{|l|}{ Month } \\
\hline January & $00: 24$ & $0: 29$ & $(00: 22-00: 25)$ & 00:19 & $0: 20$ & $(00: 18-00: 20)$ \\
\hline February & $00: 23$ & $0: 24$ & $(00: 22-00: 25)$ & $00: 19$ & $0: 19$ & $(00: 17-00: 20)$ \\
\hline March & $00: 21$ & $0: 22$ & $(00: 20-00: 23)$ & $00: 16$ & $0: 15$ & $(00: 15-00: 17)$ \\
\hline April & 00:20 & $0: 19$ & $(00: 18-00: 21)$ & $00: 16$ & $0: 15$ & $(00: 15-00: 17)$ \\
\hline May & $00: 22$ & $0: 25$ & $(00: 21-00: 23)$ & $00: 16$ & $0: 15$ & $(00: 15-00: 17)$ \\
\hline June & $00: 22$ & $0: 23$ & $(00: 20-00: 23)$ & $00: 16$ & $0: 17$ & $(00: 15-00: 17)$ \\
\hline July & $00: 21$ & $0: 23$ & $(00: 17-00: 24)$ & $00: 16$ & $0: 15$ & $(00: 14-00: 19)$ \\
\hline August & $00: 22$ & $0: 25$ & $(00: 21-00: 24)$ & $00: 16$ & $0: 13$ & $(00: 15-00: 17)$ \\
\hline September & $00: 21$ & $0: 22$ & $(00: 20-00: 23)$ & $00: 16$ & $0: 14$ & $(00: 15-00: 17)$ \\
\hline October & $00: 21$ & $0: 21$ & $(00: 19-00: 23)$ & $00: 17$ & $0: 15$ & $(00: 15-00: 18)$ \\
\hline November & $00: 22$ & $0: 29$ & $(00: 20-00: 24)$ & $00: 17$ & $0: 20$ & $(00: 16-00: 18)$ \\
\hline December & $00: 23$ & $0: 28$ & $(00: 21-00: 25)$ & $00: 17$ & $0: 18$ & $(00: 16-00: 19)$ \\
\hline Monthly trend & \multicolumn{6}{|c|}{ (polynomial contrast) } \\
\hline Linear & \multicolumn{3}{|l|}{$\mathrm{p}=.556$} & \multicolumn{3}{|l|}{$\mathrm{p}=.056$} \\
\hline Quadratic & \multicolumn{3}{|l|}{$\mathrm{p}=.007$} & \multicolumn{3}{|l|}{$\mathrm{p}<.001$} \\
\hline
\end{tabular}

\section{Season}

$\begin{array}{lllllll}\text { Winter } & 00: 23^{\mathrm{a}} & 0: 27 & (00: 22-00: 25) & 00: 19^{\mathrm{a}} & 0: 19 & (00: 18-00: 19) \\ \text { Spring } & 00: 21^{\mathrm{b}} & 0: 22 & (00: 20-00: 22) & 00: 16^{\mathrm{b}} & 0: 15 & (00: 16-00: 17) \\ \text { Summer } & 00: 22^{\mathrm{b}} & 0: 24 & (00: 21-00: 23) & 00: 16^{\mathrm{b}} & 0: 15 & (00: 15-00: 17) \\ \text { Autumn } & 00: 21^{\mathrm{b}} & 0: 24 & (00: 20-00: 22) & 00: 17^{\mathrm{b}} & 0: 16 & (00: 16-00: 17)\end{array}$

Seasonal trend (polynomial contrast)

$\begin{array}{lll}\text { Linear } & \mathrm{p}=.017 & \mathrm{p}<.001 \\ \text { Quadratic } & \mathrm{p}=.045 & \mathrm{p}<.001\end{array}$

@ Estimated marginal means are adjusted for age, education, and income.

Significant differences between seasons are indicated for each row in the table using subscript letters (a,b,c, etc), calculated at the .05 significance level. 
Table 5. Monthly and seasonal variation in insomnia symptoms@ (included in the Bergen Insomnia Scale).

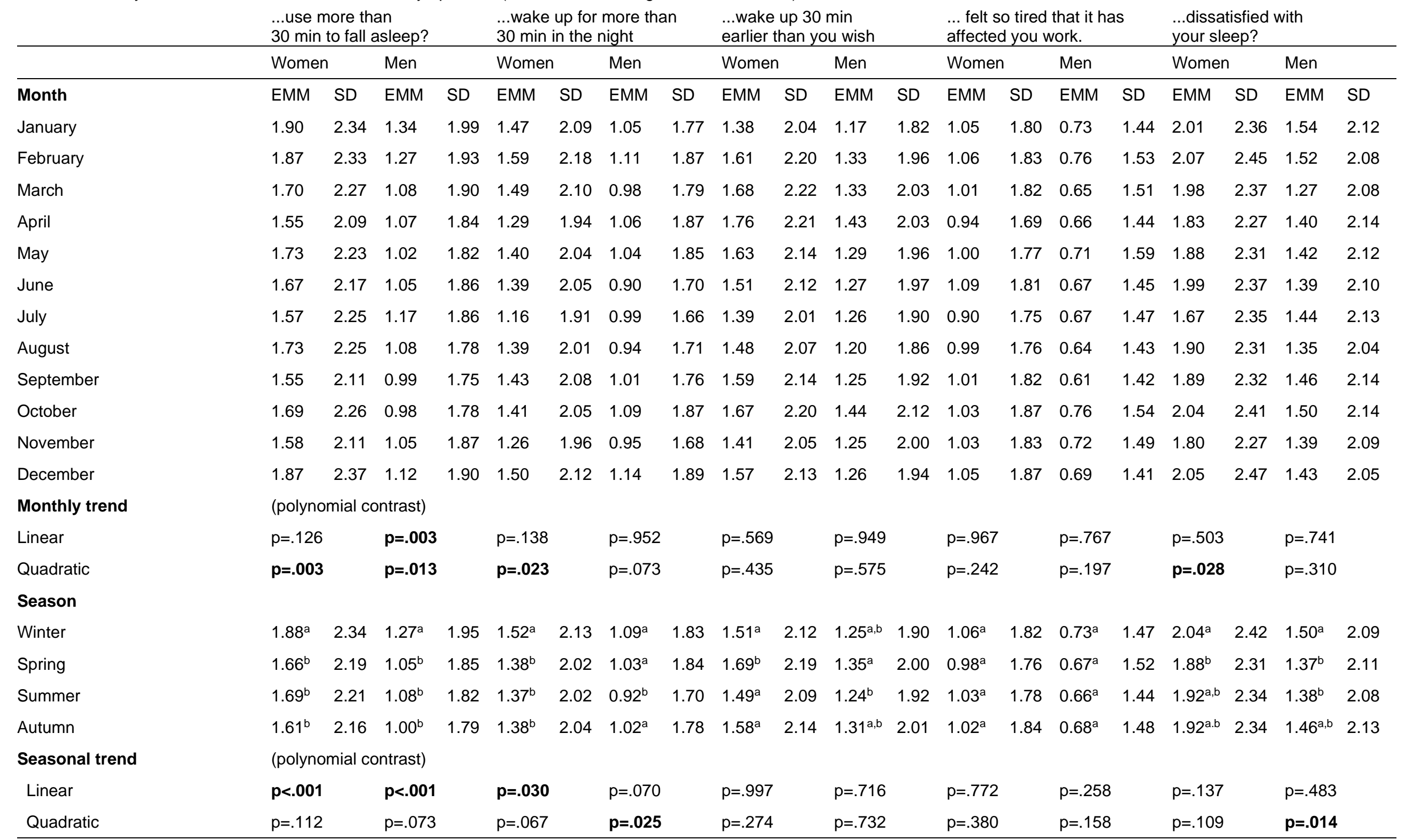

@ Estimated marginal means are adjusted for age, education, and income.

Significant differences between seasons are indicated for each row in the table using subscript letters (a,b,c, etc), calculated at the .05 significance level. 


\section{REFERENCES}

American Academy of Sleep Medicine. 2014. International Classification of Sleep Disorders. Coding (3rd ed.). Darien, IL: American Academy of Sleep Medicine.

American Psychiatric Association. 1994. Diagnostic and Statistical Manual of Mental Disorders 4 ed.). Washington, DC: American Psychiatric Publishing.

American Psychiatric Association. 2013. Diagnostic and Statistical Manual of Mental Disorders (5 ed.). Washington, DC: American Psychiatric Publishing.

Barre V, Petter-Rousseaux A. (1988). Seasonal variations in sleep-wake cycle in Microcebus murinus. Primates. 29:53-64.

Friborg O, Bjorvatn B, Amponsah B, Pallesen S. (2012). Associations between seasonal variations in day length (photoperiod), sleep timing, sleep quality and mood: a comparison between Ghana (5 degrees ) and Norway (69 degrees ). J Sleep Res. 21:176-184.

Friborg O, Rosenvinge JH, Wynn R, Gradisar M. (2014). Sleep timing, chronotype, mood, and behavior at an Arctic latitude (69 degrees N). Sleep Med. 15:798-807.

Friborg O, Sundby J, Rognmo K, Rosenvinge JH, Bergvik S, Id, Friborg OOhoo. (2018). No seasonality in cognitive performance among adolescents at a subarctic latitude (69degreeN). Applied Cognitive Psychology. 32:217-224.

Hashizaki M, Nakajima H, Shiga T, Tsutsumi M, Kume K. (2018). A longitudinal large-scale objective sleep data analysis revealed a seasonal sleep variation in the Japanese population. Chronobiol Int. 35:933-945.

Husby R, Lingjaerde O. (1990). Prevalence of reported sleeplessness in northern Norway in relation to sex, age and season. Acta Psychiatr Scand. 81:542-547.

Itani O, Kaneita Y, Munezawa T, Mishima K, Jike M, Nakagome S, Tokiya M, Ohida T. (2016). Nationwide epidemiological study of insomnia in Japan. Sleep Med. 25:130-138.

Jacobsen BK, Eggen AE, Mathiesen EB, Wilsgaard T, Njolstad I. (2012). Cohort profile: the Tromso Study. International journal of epidemiology. 41:961-967.

Johnsen MT, Wynn R, Allebrandt K, Bratlid T. (2013). Lack of major seasonal variations in self reported sleep-wake rhythms and chronotypes among middle aged and older people at 69 degrees North: the Tromso Study. Sleep Med. 14:140-148.

Johnsen MT, Wynn R, Bratlid T. (2012). Is there a negative impact of winter on mental distress and sleeping problems in the subarctic: the Tromso Study. BMC Psychiatry. 12:225.

Kasper S, Wehr TA, Bartko JJ, Gaist PA, Rosenthal NE. (1989). Epidemiological findings of seasonal changes in mood and behavior. A telephone survey of Montgomery County, Maryland. Arch Gen Psychiatry. 46:823-833.

Lowden A, Lemos NAM, Gonçalves BSB, Öztürk G, Louzada F, Pedrazzoli M, Moreno CR. (2019). Delayed Sleep in Winter Related to Natural Daylight Exposure among Arctic Day Workers. Clocks \& Sleep. 1.

Martin-Olalla JM. (2019). The long term impact of Daylight Saving Time regulations in daily life at several circles of latitude. Sci Rep-Uk. 9.

Ohayon MM, Partinen M. (2002). Insomnia and global sleep dissatisfaction in Finland. J Sleep Res. 11:339-346.

Orne MT. (1962). On the social psychology of the psychological experiment: With particular reference to demand characteristics and their implications. American Psychologist. 17.

Overland S, Woicik W, Sikora L, Whittaker K, Heli H, Skjelkvale FS, Sivertsen B, Colman I. (2019). Seasonality and symptoms of depression: A systematic review of the literature. Epidemiol Psychiatr Sci. 29:e31.

Pallesen S, Bjorvatn B, Nordhus IH, Sivertsen B, Hjornevik M, Morin CM. (2008). A new scale for measuring insomnia: the Bergen Insomnia Scale. Percept Mot Skills. 107:691-706.

Pallesen S, Nordhus IH, Nielsen GH, Havik OE, Kvale G, Johnsen BH, Skjotskift S. (2001). Prevalence of insomnia in the adult Norwegian population. Sleep. 24:771-779.

Portaluppi F, Smolensky MH, Touitou Y. (2010). Ethics and methods for biological rhythm research on animals and human beings. Chronobiol Int. 27:1911-1929. 
Rosenthal N, Bradt G, Wehr T. (1987). Seasonal Pattern Assessment Questionnaire (SPAQ). Washington, DC: National Institute of Mental Health.

Rosenthal NE, Sack DA, Gillin JC, Lewy AJ, Goodwin FK, Davenport Y, Mueller PS, Newsome DA, Wehr TA. (1984). Seasonal affective disorder. A description of the syndrome and preliminary findings with light therapy. Arch Gen Psychiatry. 41:72-80.

Shephard RJ, Aoyagi Y. (2009). Seasonal variations in physical activity and implications for human health. Eur J Appl Physiol. 107:251-271.

Sivertsen B, Overland S, Krokstad S, Mykletun A. (2011). Seasonal variations in sleep problems at latitude 63 degrees -65 degrees in Norway: The Nord-Trondelag Health Study, 1995-1997. Am J Epidemiol. 174:147-153.

Sivertsen B, Pallesen S, Friborg O, Nilsen KB, Bakke OK, Goll JB, Hopstock LA. (2020). Sleep patterns and insomnia in a large population-based study of middle-aged and older adults: The Tromso study 2015-2016. J Sleep Res.e13095.

Suzuki M, Taniguchi T, Furihata R, Yoshita K, Arai Y, Yoshiike N, Uchiyama M. (2019). Seasonal changes in sleep duration and sleep problems: A prospective study in Japanese community residents. Plos One. 14:e0215345.

Thorleifsdottir B, Bjornsson JK, Benediktsdottir B, Gislason T, Kristbjarnarson H. (2002). Sleep and sleep habits from childhood to young adulthood over a 10-year period. J Psychosom Res. 53:529-537.

Volkov J, Rohan KJ, Yousufi SM, Nguyen MC, Jackson MA, Thrower CM, Postolache TT. (2007). Seasonal changes in sleep duration in African American and African college students living in Washington, D.C. ScientificWorldJournal. 7:880-887.

Weinberger DM, Krause TG, Molbak K, Cliff A, Briem H, Viboud C, Gottfredsson M. (2012). Influenza epidemics in Iceland over 9 decades: changes in timing and synchrony with the United States and Europe. Am J Epidemiol. 176:649-655. 